\title{
PENANGGULANGAN RENDAHNYA KONSUMSI TTD REMAJA PUTRI MELALUI PENYULUHAN DAN PEMBENTUKAN DUTA REMAJA
}

\author{
Devia Lestari'1), M. Norji Arbaen'1), Odelia Bernadette Butar Butar'1), Ayu Riana Sari'1) \\ 1)Program Studi Kesehatan Masyarakat, Fakultas Kedokteran, Universitas Lambung Mangkurat, Banjarmasin, \\ Kalimantan Selatan, Indonesia \\ Corresponding author : Ayu Riana Sari \\ E-mail : devialestari542@gmail.com
}

Diterima 26 Mei 2021, Direvisi 20 Juni 2021, Disetujui 01 Juli 2021

\begin{abstract}
ABSTRAK
Anemia adalah keadaan dimana kadar hemoglobin dalam darah kurang dari normal. Remaja putri memiliki resiko 10 kali lebih besar untuk menderita anemia. Kegiatan ini bertujuan untuk meningkatkan pengetahuan dan sikap remaja putri terhadap konsumsi tablet tambah darah. Lokasi pelaksanaan kegiatan dilaksanakan di Desa Aluh-Aluh Besar RT.04 Kecamatan Aluh-Aluh Kabupaten Banjar yang dilakukan saat pandemic Covid-19. Dalam kegiatan ini dilakukan secara daring online melalui Whatsapp Group dengan subjek yang mengikuti kegiatan berjumlah 14 remaja putri. Kegiatan ini terdiri 3 tahapan meliputi: tahapan persiapan yaitu pengumpulan kontak remaja putri serta pembuatan media, tahapan kegiatan yaitu pemberian pretest dan posttest serta pemberian materi, dan tahapan monitoring dan evaluasi meliputi pemantauan dan pengawasan kegiatan penyuluhan serta menilai peningkatan dalam pengetahuan tablet tambah darah. Data diperoleh dari hasil pretest dan posttest. Hasil kegiatan ini terdapat perbedaan yang signifikan antara pengetahuan remaja putri pada saat pengisian kuesioner sebelum dan sesudah penyuluhan dan ada perbedaan antara sikap remaja putri di pada saat pengisian kuesioner sebelum dan sesudah penyuluhan.
\end{abstract}

Kata Kunci: anemia, tablet tambah darah, remaja putri

\begin{abstract}
Anemia is a condition in which the hemoglobin level in the blood is less than normal. Girls are 10 times more likely to suffer from anemia. This activity aims to increase the knowledge and attitudes of young women towards the consumption of blood-added tablets. The location of the activity was carried out in Aluh-Aluh Besar Village RT.04 Aluh-Aluh District, Banjar Regency which was carried out during the Covid-19 pandemic. Subjects who attended lessons were 14 young women. The activity consists of 3 stages of preparation, preparation phase the contacts of young women and making media, activity phase of presenting pretest and posttest and presenting material, and the stages of monitoring and evaluating activities and monitoring activities as well as assessing the increase in Fe Tablets knowledge. Data obtained from the results of the pretest and posttest. The result of this activity is that there is a significant difference between the knowledge of young women when filling out the questionnaire before and after counseling and there is a difference between the attitudes of young women when filling out the questionnaire before and after extension.
\end{abstract}

Keywords: anemia; Fe tablets; female

\section{PENDAHULUAN}

Remaja merupakan masa tumbuh kembang manusia setelah masa anak-anak dan sebelum masa dewasa. Pada masa remaja terjadi perubahan fisik dan seksual yang signifikan. Perubahan fisik yang pesat disertai perubahan hormonal pada masa remaja memicu beberapa masalah kesehatan serius salah satunya adalah anemia. Anemia merupakan salah satu masalah kesehatan masyarakat terutama pada remaja putri (Febianingsih, 2019). Anemia adalah suatu keadaan dimana kadar hemoglobin dalam darah kurang dari normal. Remaja putri memiliki resiko 10 kali lebih besar untuk menderita anemia (Yusmaharani et al, 2019). Prevalensi kejadian anemia pada remaja putri di Indonesia justru mengalami peningkatan dari $37,1 \%$ pada Riskedas 2013 yang menjadi 48,9\% pada Riskesdas 2018, dengan proporsi anemia ada di kelompok umur 15-24 tahun dan 25-34 tahun (Kemenkes RI, 2018).

Anemia disebabkan oleh rendahnya asupan zat besi dari makanan sehari-hari baik dari makanan alami maupun melalui suplementasi. Asupan zat besi dapat 
didapatkan melalui suplementasi zat besi atau Tablet Tambah Darah (TTD). Kurangnya konsumsi tablet tambah darah memiliki dampak negatif bagi kesehatan seperti lemah dan lesu sehingga menurunkan produktivitas. Adapun dampak jangka panjangnya adalah mengganggu kehamilan, berisiko meningkatkan kematian ibu, dan berisiko melahirkan bayi premature dan berat badan bayi lahir rendah (BBLR). Salah satu upaya yang telah dilakukan pemerintah dalam menanggulangi masalah anemia adalah melalui pemberian suplementasi TTD berupa zat besi (60 mg FeSO4) dan asam folat $(0,40 \mathrm{mg})$ (Permatasari et al, 2018). Namun berdasarkan hasil Riskesdas 2018 cakupan konsumsi Tablet Tambah Darah (TTD) remaja putri masih rendah. Sebanyak $76,2 \%$ remaja putri yang mendapatkan TTD, hanya 1,4\% yang mengkonsumsi $\geq 52$ butir. Sedangkan 98,6\% remaja mengkonsumsi $<52$ butir. Berdasarkan data Kalimantan Selatan, pada kelompok umur 10-19 tahun 97,7\% mengkonsumsi TTD $<52$ butir. Alasan utama remaja putri tidak menghabiskan TTD yang diperoleh dengan inisiatif sendiri 39,7 karena merasa tidak perlu, hal ini terjadi dikarenakan salah satu faktor yang mempengaruhi adalah rendahnya pengetahuan terkait anemia dan pentingnya konsumsi Tablet Tambah Darah (TTD) (Kemenkes RI, 2019).

Kegiatan pengabdian ini dilakukan di Kecamatan Aluh-Aluh Desa Aluh-Aluh Besar RT.04. Berdasarkan data sumber primer diagnosa komunitas masyarakat di Desa AluhAluh Besar RT.04, ditemukan permasalahan kesehatan yaitu kurangnya konsumsi tablet tambah darah pada remaja putri. Dari 15 remaja putri yang ada di RT. 04 hanya 20\% (3 remaja putri) yang mengkonsumsi TTD sedangkan sisanya yaitu $80 \%$ tidak mengkonsumsi tablet tambah darah. Kepatuhan minum tablet tambah darah dipengaruhi oleh dua faktor utama, yaitu faktor dari petugas kesehatan dan faktor dari diri sendiri seperti kesadaran dalam mengkonsumsi tablet Fe. Kepatuhan dalam mengkonsumsi suplementasi zat besi atau pemberian tablet $\mathrm{Fe}$ sangat mempengaruhi perubahan kadar hemoglobin, dimana kadar hemoglobin yang normal maka status anemia juga akan normal, sehingga dapat mencegah dan menanggulangi anemia defisiensi besi (Nuradhiani A, 2017).

Oleh karena itu, perlu adanya upaya penanggulangan rendahnya cakupan konsumsi tablet tambah darah pada remaja putri melalui penyuluhan dan pembentukan duta remaja putri konsumsi tablet tambah darah untuk meningkatkan pengetahuan dan sikap remaja putri. Pengetahuan yang baik dan sikap yang baik mengenai tablet tambah darah akan membentuk perilaku yang baik pula pada remaja putri yaitu meningkatnya cakupan konsumsi tablet tambah yang manfaatnya mengurangi kemungkinan kelainan yang merupakan dampak jangka pendek dan jangka panjang akibat tidak mengkonsumsi tablet tambah darah.

\section{METODE}

Penanggulangan rendahnya konsumsi tablet tambah darah pada remaja putri dilakukan melalui penyuluhan dan pementukan duta konsumsi tablet tambah darah. Kegiatan ini dilaksanakan secara daring melalui whatsapp group. Sasaran atau target dari kegiatan ini adalah remaja putri yang tinggal di Desa Aluh-Aluh Besar RT 04 Kecamatan Aluhaluh Kabupaten Banjar dan aktif menggunakan sosial media whatsapp.

Pelaksanaan kegiatan ini dilakukan dengan menggunakan media booklet dan vidio animasi yang dibuat semenarik mungkin baik dari warna sampai dengan gambar sebagai sarana dalam menyampaikan materi, tujuannya untuk mempermudah remaja putri dalam memahami pesan yang akan disampaikan, yang harapannya juga dapat menambah pengetahuan serta merubah sikap dan perilaku remaja putri dalam mengkonsumsi tablet tambah darah.

Kegiatan ini dibagi menjadi 3 tahap yaitu tahap persiapan, tahap pelaksanaan kegiatan, dan monitoting dan evaluasi.

Tahap I: Persiapan

Pada tahap ini merupakan persiapan yang dilakukan sebelum kegiatan diantaranya mengumpulkan kontak remaja putri agar dimasukan kedalam whatsapp group, penyusunan soal pretest dan posttest, serta pembuatan media untuk penyampaian materi yaitu booklet dan vidio animasi.

Tahap II: Pelaksanaan kegiatan

Pelaksanaan kegiatan dimulai dengan melakukan pretest melalui google formulir yang disebarkan melalui whatsapp group, pretest dilakukan untuk mengukur pengetahuan remaja putri mengenai konsumsi tablet tambah darah sebelum diberikan materi. Kemudian dilanjutkan dengan pemberian materi dengan mengirimkan vidio animasi dan booklet serta dilakukan sesi diskusi setelah remaja putri selesai menonton vidio dan membaca booklet. Setelah sesi diskusi selesai dilakukan pemberian posttest dengan soal yang sama dengan pretest yang bertujuan untuk mengetahui peningkatan pengetahuan remaja putri mengenai konsumsi tablet tambah darah setelah diberikan materi. Pelaksanaan yang terakhir adalah pembentukan Duta remaja putri 
konsumsi tablet tambah darah dengan mengadakan kuis cerdas cermat.

Tahap III: Monitoring dan Evaluasi

Kegiatan monitoring dan evaluasi dilakukan pada saat kegiatan penyuluhan berlangsung dan setelah kegiatan penyuluhan selesai. Monitoring dilakukan dengan cara melakukan pemantauan dan pengawasan terhadap proses, hasil dan dampak dari kegiatan penyuluhan ini. Evaluasi dari program ini dapat dilihat dari meningkatnya pengetahuan sasaran terkait tablet tambah darah dengan menilai apakah pengetahuan yang telah dimiliki remaja putri dimanfaatkan secara efektif dan efisien dilihat dari hasil pretest dan posttest yang telah diberikan. Selain itu duta akan saling mengingatkan para remaja putri yang ada dikelompoknya untuk selalu mengkonsumsi tablet tambah darah.

\section{HASIL DAN PEMBAHASAN}

Tahap persiapan yaitu mengumpulkan nomor telepon 14 remaja putri yang dimasukkan ke dalam whatsapp group, pembuatan soal pretest dan posttest, dan pembuatan media intervensi diantaranya booklet dan vidio animasi.

Berikut adalah karakteristik responden pada kegiatan pemberian edukasi mengenai tablet tambah darah (TTD).

Tabel 1. Karakteristik Responden

\begin{tabular}{|c|c|c|}
\hline Keterangan & Jumlah & Persentase \\
\hline $\begin{array}{l}\text { Jenis } \\
\text { Kelamin }\end{array}$ & & \\
\hline $\begin{array}{l}\text { Perempuan } \\
\text { Usia }\end{array}$ & 14 orang & $100 \%$ \\
\hline $11-15$ tahun & 4 orang & $28,6 \%$ \\
\hline $16-25$ tahun & 10 orang & $71,4 \%$ \\
\hline Total & 14 orang & $100 \%$ \\
\hline
\end{tabular}

Kegiatan ini menggunakan media booklet dan vidio animasi 4 menit. Booklet adalah media cetak yang memiliki paling sedikit lima halaman dan paling banyak empat puluh delapan halaman tetapi tidak termasuk dalam hitungan sampul, yang dijilid di bagian tengah sekaligus dengan sampulnya dan desain yang menarik (Putri AO, 2021).

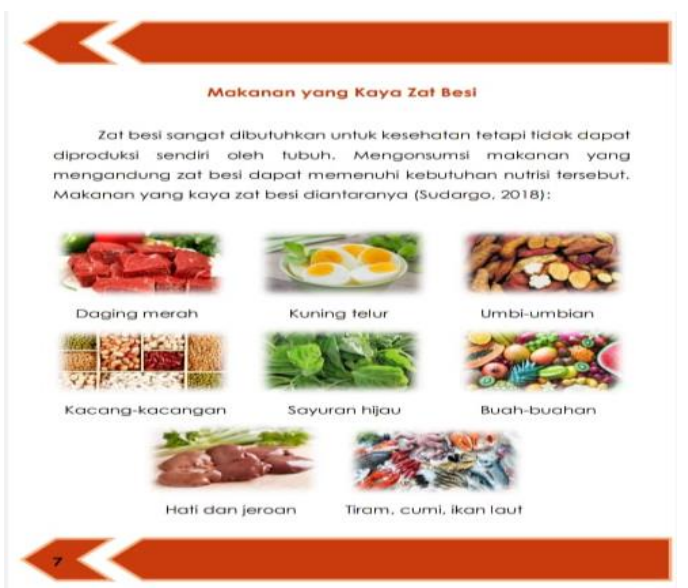

Gambar 1. Isi booklet

Video edukasi dan media booklet berisi tentang pengertian tablet tambah darah, kenapa remaja putri harus mengkonsumsi tablet tambah darah, dampak tidak mengkonsumsi tablet tambah darah, kapan remaja putri harus mengkonsumsi tablet tambah darah, cara mengkonsumsi, efek samping, dan makanan yang kaya akan zat besi.
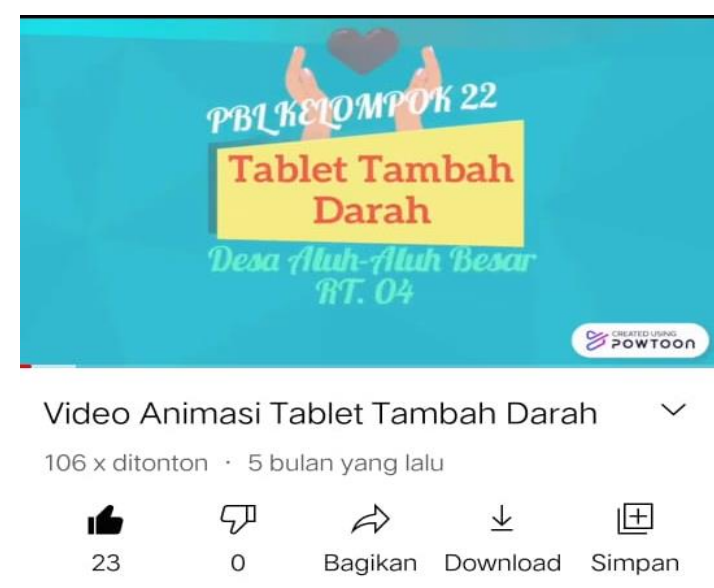

Gambar 2. Isi vidio

Pelaksanaan kegitan merupakan hasil kerja atau performance disebut juga sebagai kinerja. Kinerja pada dasarnya adalah apa yang dilakukan atau tidak dilakukan yang dalam hal ini anggota tim baik secara individu maupun secara kelompok dan organisasi (Dendeng, 2020).

Tim pengabdiaan masyarakat melakukan kegiatan berupa penyuluhan terkait Tablet Tambah Darah kepada remaja putri Desa Aluh-Aluh Besar Rt. 04 dengan jumlah peserta sebanyak 14 orang. Kegiatan ini dilaksanakan melalui Group WhatsApp "Intervensi Masyarakat RT. 04, yang dihadiri oleh pembimbing dan remaja putri Rt. 04 .

Remaja diberikan link google formulir untuk melakukan pretest. Setelah pemberian 
link google formulir, peserta remaja putri dipersilahkan untuk membuka link youtube beserta booklet agar remaja putri dapat memahami materi yang diberikan, dan kemudian akan dilakukan penyuluhan via chat whatsapp group dan melakukan sesi diskusi yang dibuka oleh tim untuk para remaja putri yang bertanya, kemudian pertanyaan tersebut didiskusikan bersama dilakukan dalam Group WhatsApp.

Kegiatan monitoring dan evaluasi merupakan hasil kegiatan yang memuat distribusi frekuensi pengetahuan dan sikap remaja putri. Serta hasil uji statistik untuk melihat perbedaan antara pengetahuan dan sikap sebelum intervensi dan sesudah intervensi.

Tabel 2. Distribusi Frekuensi Pengetahuan dan Sikap Remaja Putri Tentang Konsumsi Tablet Tambah Darah

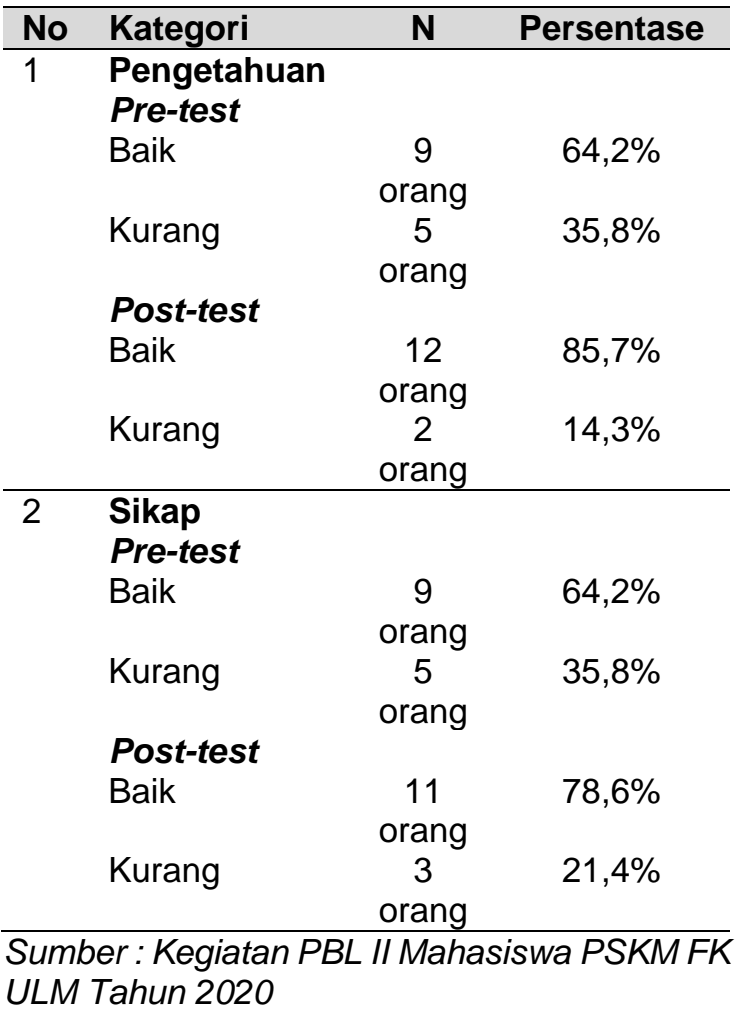

Berdasarkan Tabel 2. dapat diketahui bahwa pengetahuan responden sebelum mendapatkan materi mengenai tablet tambah darah sebagian besar termasuk dalam kategori baik yaitu sebanyak 9 orang $(64,2 \%)$. Pengetahuan responden dengan kategori baik setelah mendapatkan materi mengenai tablet tambah darah yaitu sebanyak 12 orang $(85,7 \%)$. Berdasarkan hasil tersebut diketahui bahwa terjadi peningkatan pengetahuan dengan kategori baik, dari yang sebelum mendapatkan materi $64,2 \%$ dan setelah mendapatkan materi menjadi $85,7 \%$.
Sikap responden sebelum mendapatkan materi mengenai tablet tambah darah sebagian besar termasuk dalam kategori baik yaitu sebanyak 9 orang $(64,2 \%)$. Sedangkan sikap responden setelah mendapatkan materi mengenai tablet tambah darah, bersikap baik yaitu sebanyak 11 orang $(78,6 \%)$. Berdasarkan hasil tersebut diketahui bahwa terjadi peningkatan sikap dengan kategori baik, dari yang sebelum mandapatkan materi $64,2 \%$ dan setelah mendapatkan materi menjadi $78,6 \%$.

Tabel 3. Hasil Uji Statistik Pengetahuan

Remaja Putri Tentang Konsumsi Tablet Tambah Darah

\begin{tabular}{|c|c|c|c|c|}
\hline $\begin{array}{l}\text { Jeni } \\
\text { s } \\
\text { Tes }\end{array}$ & $\mathbf{N}$ & $\begin{array}{l}\text { Rata } \\
\text {-rata }\end{array}$ & $\begin{array}{c}\text { Uji } \\
\text { Normalita } \\
s\end{array}$ & $\begin{array}{c}\text { Uji Beda } \\
\text { Rata-rata } \\
\text { (Uji } \\
\text { Wilcoxon } \\
\text { ) }\end{array}$ \\
\hline $\begin{array}{l}\text { Pre- } \\
\text { test }\end{array}$ & $\begin{array}{l}1 \\
4 \\
\end{array}$ & $\begin{array}{c}71,4 \\
2 \\
\end{array}$ & $\begin{array}{c}0,029< \\
0,05\end{array}$ & $\begin{array}{l}\text { Nilai Sig } \\
(0,001)<\end{array}$ \\
\hline $\begin{array}{l}\text { Post- } \\
\text { test }\end{array}$ & $\begin{array}{l}1 \\
4\end{array}$ & $\begin{array}{c}85,7 \\
1\end{array}$ & $\begin{array}{c}0,009< \\
0,05\end{array}$ & 0,05 \\
\hline
\end{tabular}

Sumber : Kegiatan PBL II Mahasiswa PSKM FK ULM Tahun 2020

Berdasarkan Tabel 3. diketahui bahwa baik nilai pre-test maupun post-test responden tidak berdistribusi normal karena nilai signifikansi yang kurang dari 0,05 . Sehingga pengujian dilakukan dengan uji wilcoxon. Terlihat pada uji wilcoxon nilai Sig $(0,001)<$ 0,05 berarti Ho ditolak yang artinya ada perbedaan yang signifikan antara pengetahuan remaja putri Desa Aluh-Aluh Besar RT. 04 pada saat pengisian kuesioner sebelum dan sesudah penyuluhan. Hal ini dapat terjadi karena pada saat penyuluhan, tim memberikan materi yang mudah dimengerti oleh remaja putri, dan remaja putri yang antusias dalam membaca soft file booklet yang dibagikan dan menonton video animasi mengenai tablet tambah darah melalui whatsapp group.

Hal ini sesuai dengan teori L. Green yang menyatakan bahwa perilaku seseorang tentang kesehatan tidak hanya dipengaruhi oleh pengetahuan seseorang akan tetapi ada faktor lain yaitu kepercayaan, keyakinan, budaya, tradisi dan sebagainya. Pengetahuan adalah merupakan hasil dari tahu dan ini terjadi setelah orang melakukan penginderaan terhadap suatu objek tertentu. Penginderaan terjadi melalui panca indera manusia, yakni indera penglihatan, pendengaran, penciuman, rasa dan raba dengan sendiri. Pada waktu penginderaan sampai menghasilkan pengetahuan tersebut sangat dipengaruhi oleh intensitas perhatian persepsi terhadap objek. Sebagian besar pengetahuan manusia diperoleh melalui mata dan telinga (Notoadmojo, 2012). Terdapat 
perbedaan yang signifikan pada pengetahuan remaja putri Desa Aluh-Aluh Besar RT. 04 antara sebelum penyuluhan dengan sesudah penyuluhan, sehingga didapatkan bahwa ada pengaruh pemberian materi melalui whatsapp group terhadap peningkatan pengetahuan remaja putri terhadap pentingnya mengonsumsi tablet tambah darah. Hal ini sejalan dengan penelitian Nur Fatimah (2020) bahwa terdapat perbedaan antara sebelum dan sesudah diberikan penyuluhan dengan nilai p-value $(0,0001)$. Adanya interaksi antara remaja putri dan tim penelitian memunculkan rasa ingin tahu mengenai tablet tambah darah, selain itu materi yang diberikan dengan cara yang menarik dan mudah dipahami (Fatimah N, 2019).

Tabel 4. Hasil Uji Statistik Sikap Remaja Putri

Tentang Konsumsi Tablet Tambah Darah

\begin{tabular}{|c|c|c|c|c|}
\hline $\begin{array}{l}\text { Jenis } \\
\text { Tes }\end{array}$ & $\mathbf{N}$ & $\begin{array}{l}\text { Rata- } \\
\text { rata }\end{array}$ & $\begin{array}{c}\text { Uji } \\
\text { Normalitas }\end{array}$ & $\begin{array}{c}\text { Uji } \\
\text { Beda } \\
\text { Rata- } \\
\text { rata } \\
\text { (Uii T) }\end{array}$ \\
\hline $\begin{array}{l}\text { Pre- } \\
\text { test }\end{array}$ & 14 & 75 & $\begin{array}{c}0,080< \\
0,05\end{array}$ & $\begin{array}{l}\text { Nilai } \\
\text { Sig }\end{array}$ \\
\hline $\begin{array}{l}\text { Post- } \\
\text { test }\end{array}$ & 14 & 78,45 & $\begin{array}{c}0,174< \\
0,05\end{array}$ & $\begin{array}{l}(0,001) \\
<0,05\end{array}$ \\
\hline
\end{tabular}

Sumber : Kegiatan PBL II Mahasiswa PSKM FK ULM Tahun 2020

Berdasarkan Tabel 4. diketahui bahwa baik nilai pre-test maupun post-test responden berdistribusi normal karena nilai signifikansi yang lebih dari 0,05 . Sehingga pengujian dilakukan dengan uji T (Paired sample $t$ test). Terlihat pada uji T nilai Sig $(0,001)<0,05$ berarti Ho ditolak yang artinya ada perbedaan antara sikap remaja putri di Desa Aluh-Aluh Besar RT. 04 pada saat pengisian kuesioner sebelum dan sesudah penyuluhan.

Sikap merupakan kesiapan atau kesediaan seseorang untuk bertindak dan bukan merupakan pelaksanaan motif tertentu. Dengan kata lain, fungsi sikap belum merupakan suatu tindakan (reaksi terbuka) atau sebuah aktivitas, tetapi sikap merupakan terdisposisi dari perilaku (tindakan) atau reaksi tertutup (Hasna et al, 2020). Terdapat perbedaan antara sikap remaja putri di Desa Aluh-Aluh Besar RT. 04 antara sebelum penyuluhan dengan sesudah penyuluhan. Hal ini sejalan dengan penelitian Rahmiati et al (2020) bahwa terdapat perbedaan sikap remaja putri sebelum dan sesudah pendidikan gizi pada program suplementasi zat besi dengan nilai $p$-value $<0,05$. Sikap merupakan reaksi positif atau negatif yang masih didalam perasaan belum sampai melakukan tindakan. Sikap dipengaruhi oleh pengetahuan, pengetahuan yang baik akan menimbulkan sikap yang baik karena adanya perubahan persepsi pada saat remaja putri mendapatkan pengetahuan (Rahmiati et al, 2019).

Remaja putri melakukan penilaian terhadap booklet dan video yang digunakan sebagai media oleh tim pengabdian. Dari penilaian media booklet didapatkan 89,6\% remaja putri menyatakan isi booklet sangat baik, $85,6 \%$ remaja putri menyatakan tampilan booklet sangat baik, dan $100 \%$ remaja putri menyatakan bahwa booklet tersebut bermanfaat. Dari penilaian media video didapatkan $87,2 \%$ remaja putri menyatakan isi video sangat baik, $84 \%$ remaja putri menyatakan tampilan video sangat baik, dan $100 \%$ remaja putri menyatakan bahwa video tersebut bermanfaat. Media pembelajaran bermanfaat untuk memperkuat pembelajaran, memotivasi pelajar, dan melakukan pembelajaran yang nyata. Adanya penyuluhan mengenai Tablet Tambah Darah dengan menggunakan booklet dan video memberikan penguatan dan pengetahuan bagi masyarakat, khususnya bagi remaja putri (Rehusisma et al, 2017).

Pelaksanaan yang terakhir adalah pembentukan duta remaja putri konsumsi tablet tambah darah dengan mengadakan kuis cerdas cermat. Hasil kuis pemilihan duta remaja putri konsumsi TTD di desa Aluh-Aluh Besar RT. 04 didapatkan 2 duta yang terpilih dengan perolehan skor tertinggi. Kuis pemilihan duta terdiri dari soal pengetahuan tentang tablet tambah darah dan ketersediaan remaja putri untuk menjadi Duta remaja putri konsumsi TTD. Inisial AS mendapatkan total skor tertinggi sebesar 218 dan ditetapkan menjadi Duta I remaja putri konsumsi TTD sedangkan inisial NA mendapatkan total skor tertinggi kedua sebesar 209 dan ditetapkan menjadi Duta II remaja putri konsumsi TTD.

Tugas yang dilakukan duta remaja putri konsumsi TTD diantaranya adalah:

1. Menyebarkan poster mengenai materi tablet tambah darah yang sudah disediakan oleh kelompok 22 PBL. Poster di upload di sosial media duta (seperti whatsapp atau instagram). Poster diuplod sebanyak 2x24 jam dalam 1 bulan, tiap bulan poster yang di sebarkan berbeda topiknya, sehingga ada 6 topik mengenai tablet tambah darah selama 6 bulan kepengurusan duta.

2. Remaja putri dibagi menjadi dua kelompok dan duta ditempatkan pada masingmasing kelompok untuk membagian tablet tambah darah kepada remaja putri dikelompoknya. Tablet tambah darah diberikan oleh Puskesmas Aluh-aluh. 
3. Duta mengingatkan dan mencatat remaja putri yang ada dikelompoknya mengkonsumsi tablet tambah darah, remaja putri dalam melaporkannya dalam bentuk foto saat mengkonsumsi TTD dan mengirimkan kepada duta 1 minggu sekali.

Adapun rencana tidak lanjut dari intervensi ini adalah refresh pengetahuan remaja putri dengan penyuluhan berkala, melakukan monitoring satu bulan sekali antara tim PBL dan duta remaja putri konsumsi TTD selama 6 bulan, dan melakukan evaluasi sebanyak 3 bulan sekali dalam 6 bulan kepengurusan duta remaja putri konsumsi TTD. Refresh pengetahuan remaja putri ini bertujuan untuk melihat serta mengukur pengetahuan dari remaja putri, apakah pengetahuannya terhadap tablet tambah darah meningkat atau menurun. Monitoring ini bertujuan untuk melihat apakah duta menjalankan tugasnya untuk menyebarkan informasi mengenai pentingnya tablet tambah darah dan untuk melihat apakah terdapat peningkatan konsumsi tablet tambah darah pada remaja putri. Evaluasi ini bertujuan untuk tahap penilaian keberhasilan dan perbaikan pada kegiatan berikutnya, selain itu dilakukan pengecekan kadar hemoglobin pada remaja putri.

\section{SIMPULAN DAN SARAN Simpulan}

Intervensi kegiatan dilakukan secara online dikarenakan situasi pandemi covid-19. Kegiatan yang dilakukan berupa penyuluhan terkait Tablet Tambah Darah (TTD) kepada remaja putri Desa Aluh-Aluh Besar RT. 04 melalui group WhatsApp. Para remaja putri Desa Aluh-Aluh Besar RT. 04 sangat antusias dan bersemangat dalam mengikuti kegiatan intervensi, hal itu dapat dilihat dari hasil intervensi terkait penyuluhan Tablet Tambah Darah (TTD) pada remaja putri Desa Aluh-Aluh Besar RT. 04 didapatkan bahwa terjadi peningkatan rata-rata nilai pengetahuan dan sikap mengenai Tablet Tambah Darah (TTD). Selain itu diketahui ada perbedaan antara sikap remaja putri di Desa Aluh-Aluh Besar RT. 04 pada saat pengisian kuesioner sebelum dan sesudah penyuluhan. Dari intervensi yang dilakukan maka terpilih dua remaja sebagai Duta Remaja Putri Konsumsi TTD yang dipilih dengan mengadakan kuis cerdas cermat. Hasil kuis cerdas cermat didapatkan dengan nilai skor tertinggi pertama sebesar 218 dan skor tertinggi kedua sebesar 209, yang akhirnya terpilih menjadi Duta Remaja Putri Konsumsi TTD.

Saran

Perlu adanya sosialisasi serta promosi mengenai konsumsi tablet tambah darah oleh pihak Puskesmas dan sekolah yang ada di Desa Aluh-Aluh Besar. Selain itu perlu dilakukan pendampingan dan monitoring dari guru dan orang tua secara berkesinambungan kepada para remaja putri agar dapat meningkatkan perilaku dalam konsumsi tablet tambah darah.

\section{UCAPAN TERIMAKASIH}

Terima kasih kepada kepala desa Desa Aluh-aluh besar dan ketua RT 04 telah membantu dalam kegiatan ini, serta dosen pembimbing dan rekan sejawat yang telah membantu dalam pelaksanaan kegiatan ini sehingga kegiatan ini dapat berjalan lancar sesuai dengan yang diharapkan.

\section{DAFTAR RUJUKAN}

Dendeng FG, Salmin D, Very YL. Kemampuan pelaksanaan fungsi dewan perwakilan rakyat daerah Kabupaten Minahasa Utara. Jurnal Administrasi Publik 2020; 6(94): 1-12.

Fatimah, N. (2020). Perbedaan pengetahuan remaja putri sebelum dan sesudah diberikan penyuluhan tentang tablet tambah darah ( $\mathrm{Fe}$ ) di SMK Kanisius Ungaran. Skripsi Program Studi D-IV Kebidanan Universitas Ngudi Waluyo.

Febianingsih. (2019). Prevalensi factor risiko anemia pada remaja putri di SMAN Abiansemal Badung. Bali Health Published Journal, 1(1), 47-58.

Hasna, C. R., et al. (2020). Gambaran Pengetahuan, Sikap dan Kepatuhan Konsumsi Tablet Tambah Darah (TTD) Pada Remaja Putri di SMPN 1 Gegesik Kabupaten Cirebon [Thesis]. Bandung: Politeknik Kesehatan Kemenkes.

Notoatmodjo, S. (2012). Promosi Kesehatan dan Perilaku Kesehatan. Jakarta: Rineka Cipta.

Nuradhiani A, Dodik B, Cesilia MD. (2017). Dukungan guru meningkatkan kepatuhan konsumsi tablet tambah darah pada remaja putri di kota Bogor. Jurnal Gizi Pangan, 12(3), 153-160.

https://doi.org/10.25182/jgp.2017.12.3.1 $\underline{53-160}$

Permatasari, T., Briawan, D., \& Madanijah, S. (2018). Efektivitas Program Suplementasi Zat Besi pada Remaja Putri di Kota Bogor (Effectiveness of Iron Supplementation Programme in Adolescent girl at Bogor City). Jurnal Media Kesehat Masy Indonesia, 14(1), $1-8$.

https://doi.org/10.30597/mkmi.v14i1.37 $\underline{05}$ 
Putri AO, Tyas NR, Aulia RC, dkk. (2021). Penyuluhan Online Dengan Booklet Dan Video Sebagai Upaya Pengendalian Hipertensi. SELAPARANG. Jurnal Pengabdian Masyarakat Berkemajuan, 4(2), 451458.

Rahmiati, B. F., Wayan C. N., \& Junendri, A. (2019). Efektivitas intervensi pendidikan gizi pada program suplementasi besi terhadap pengetahuan, sikap, dan perilaku. Jurnal Gizi dan Kesehatan, 3(2), 47-51. https://doi.org/10.22487/ghidza.v3i2.20

Rehusisma, L. A., Indriwati, S. E., \& Suarsini, E. (2017). Pengembangan media pembelajaran booklet dan video sebagai penguatan karakter hidup bersih dan sehat. Jurnal Pendidikan: Teori, Penelitian, dan Pengembangan, 2(9), 1238-1243. http://dx.doi.org/10.17977/jptpp.v2i9.99 $\underline{64}$

Yusmaharani, Y., Lora, M., \& Dewi, S. S. (2019). "Cerdas tanggap dalam pencegahan anemia di SMAN I Rumbio Jaya Tapung". Dinamisia : Jurnal Pengabdian Kepada Masyarakat, 3(1), pp. 100-104. doi: 10.31849/dinamisia.v3i1.2146.

https://doi.org/10.31849/dinamisia.v3i1 .2146

Kemenkes RI. (2019). Laporan Nasional Riset Kesehatan Dasar (Riskesdas) 2018. Jakarta: Balitbangkes.

Kemenkes RI. (2018). Pesan untuk remaja putri Indonesia: Cantik itu sehat, bukan kurus. November 22, 2018 from https://www.kemkes.go.id/article/view/ 18112300003/pesan-untukremajaputri-indonesia-cantik-itu-sehatbukan

kurus.html\#: :text=Belum\%20lagi\%20t antangan\%20anemia\%20pada,tahun\% 20dan\%2025\%2D34\%20tahun. 